\title{
ANATOMIA DA MADEIRA DE DUAS ESPÉCIES DE MIMOSA DA SÉRIE STIPELLARES BENTH. ${ }^{1}$
}

\author{
PAULO FERNANDO DOS SANTOS MACHADO ${ }^{2}$ \\ JOSÉ NEWTON CARDOSO MARCHIORI ${ }^{3}$ TALITA BALDIN $^{4}$
}

\section{RESUMO}

São anatomicamente descritos e ilustrados com fotomicrografias os lenhos de Mimosa barnebiana e Mimosa bifurca. O exame da estrutura anatômica de ambas as espécies e a comparação das mesmas com outras da série Stipellares Benth., constantes na literatura, demonstra que a presença de poros em numerosos múltiplos e em arranjo nítido ou tendente a diagonal (dendrítico) é traço comum a todo o grupo e, dentro do gênero Mimosa, observado apenas em espécies da referida série botânica.

Palavras-chave: anatomia da madeira, Fabaceae, Leguminosae, Mimosa, Mimosaceae, Mimosa barnebiana, Mimosa bifurca, Mimosoideae, Stipellares.

ABSTRACT.

[Wood anatomy of two species of Mimosa from the series Stipellares Benth.].

The woods of Mimosa barnebiana and Mimosa bifurca are anatomically described and illustrated with photomicrographs. The examination of anatomical structures from both woods and the comparison with other species from Stipellares series, listed in the literature, shows that pores in large multiples and in a distinct (or tending to) diagonal pattern (dendritic) is a feature common to all species from the group and, within genus Mimosa, observed only in species of that botanical series.

Keywords: Fabaceae, Leguminosae, Mimosa, Mimosaceae, Mimosa barnebiana, Mimosa bifurca, Mimosoideae, Stipellares, wood anatomy.

\section{INTRODUÇÃO}

Parte de um projeto mais amplo e que tem o objetivo de investigar caracteres anatômicos de valor diagnóstico no lenho de distintos táxons infragenéricos de Mimosa L., a presente pesquisa trata da descrição microscópica da madeira de duas espécies da série Stipellares Benth. (Mimosa barnebiana Fortunato \& Tressens e Mimosa bifurca Benth.), com base em material coletado no Rio Grande do Sul.

1 Recebido em 10-5-2016 e aceito para publicação em 15-7-2016.

2 Engenheiro Florestal, doutorando do Programa de PósGraduação em Engenharia Florestal, Universidade Federal de Santa Maria. Santa Maria, RS, Brasil. barcasole@gmail.com

3 Engenheiro Florestal, Dr. Bolsista de Produtividade em Pesquisa (CNPq - Brasil). Professor Titular do Departamento de Ciências Florestais, Universidade Federal de Santa Maria.

4 Engenheira Florestal, doutoranda do Programa de PósGraduação em Engenharia Florestal, Universidade Federal de Santa Maria.

\section{REVISÃO DE LITERATURA}

Com cerca de 540 espécies, Mimosa L. é o segundo maior gênero da subfamília Mimosoideae e inclui-se na tribo Mimoseae, que reúne 870 espécies, aproximadamente, agrupadas em 40 gêneros. Predominantemente neotropical, sua distribuição natural estende-se à ilha de Madagascar, onde existem 31 espécies, aproximadamente, bem como à África e Ásia, com cerca de quatro espécies em cada um destes continentes (Santos-Silva et al., 2015).

Em seu clássico "Genera plantarum", Linnaeus (1754) reuniu em Mimosa quase todas as espécies da atual subfamília Mimosoideae até então conhecidas, segregando-as, com base na presença de legumes articulados, cilíndricos e carnosos, nos táxons infragenéricos Mimosae, Acaciae e Ingae, respectivamente. Antes da referida obra, cabe lembrar que outros botânicos já haviam concebido gêneros mais naturais no grupo, casos de Acacia, reconhecido por Tournefort (1694) e Inga, por Plumier (1703). 
A respeito da contribuição do "Pai da nomenclatura binomial" ao tema em foco, resta salientar que suas 47 espécies de Mimosa foram posteriormente distribuídas em 16 gêneros (Burkart, 1948).

Com base em caracteres do fruto, Willdenow (1805) segregou os gêneros Acacia, Desmanthus, Inga e Schrankia de Mimosa L., salientando-se, ainda, que algumas de suas espécies de Mimosa foram posteriormente transferidas a gêneros como Albizzia, Piptadenia, Parapiptadenia e Newtonia, entre outros.

$\mathrm{Na}$ taxonomia de Mimosa salientam-se os estudos magistrais de George Bentham e Rupert C. Barneby, distanciados entre si por um lapso de mais de cem anos.

Ainda no século dezenove, Bentham (1842, 1875) organizou as espécies de Mimosa em duas seções - Eumimosa DC. e Habbasia Benth. -, distintas entre si pela presença de flores haplostêmones e diplostêmones, respectivamente. Para a última, Bentham (1876) reconheceu nove séries botânicas em sua contribuição para a "Flora Brasiliensis": Leptostachyae, Glanduliferae, Rubicaules, Stipellares, Leptopodae, Somnianthes, Asperatae, Adversae e Pachycarpae. Na caracterização da série Stipellares, o botânico inglês valeu-se, sobretudo, de caracteres morfológicos, como capítulos globosos, legumes subplanos de valvas indivisas, estipelas orbiculares ou ovais, e folíolos pouco abundantes.

Em "Sensitivae Censitae", Barneby (1991) elaborou um novo (e complexo) esquema para Mimosa L., composto de cinco seções (Batocaulon DC., Calothamnos Barneby, Habbasia DC., Mimadenia Barneby e Mimosa L.), 41 séries e 37 subséries. A partir de ancestrais Piptadenióides, a seção Mimadenia foi a primeira a ser tratada em seu "hipotético" esquema filogenético, seguida pela seção Batocaulon, à qual teria dado origem às seções Calothamnos e Habbasia; a partir desta última, por fim, ter-se-ia derivado a seção Mimosa (Barneby, 1991).
Na elaboração de seu esquema, o botânico anglo-americano valeu-se de alguns táxons infragenéricos propostos por George Bentham. É o caso, entre outros, da série Stipellares Benth., que foi reunida a outras 24 para compor a seção Batocaulon DC., e que se distingue, do conjunto, pela presença de flores tetrâmeras e em capítulos (com exceção de M. barnebiana, que apresenta verdadeiras espigas), de estípulas com forma variável, embora nunca foliáceas, e de parafilídios elípticos, ovados, reniformes ou suborbiculares, simulando diminutos folíolos.

Para a série Stipellares, Barneby (1991) reconheceu 19 espécies válidas, concentradas no Brasil extratropical, Paraguai, centro-norte da Argentina e Uruguai, salientando haver escassos representantes no estado de São Paulo, no departamento de Amambay (Paraguai) e uma espécie isolada na Bolívia (Mimosa lepidota), na encosta leste dos Andes.

A respeito da classificação infragenérica de Barneby, estudos filogenéticos recentes (Luckow et al., 2000; Sulaiman et al., 2003; Bessega et al., 2008; Simon et al., 2011) demonstram que o gênero Mimosa compõe um grupo monofilético, embora não se possa dizer o mesmo da maioria das seções e séries de seu esquema (Santos-Silva et al, 2015).

No presente estudo são anatomicamente investigadas duas espécies de madeira da série Stipellares: Mimosa barnebiana e Mimosa bifurca.

Nativa de solos arenosos e campos inundados, em ilhas do rio Paraná (localidade típica), à jusante de Posadas (Argentina), Mimosa barnebiana foi descrita apenas no último quartel do século vinte (Fortunato \& Tressens, 1989) e distingue-se pela invulgar combinação de indumento glandular-setuloso com os típicos parafilídios da série Stipellares Benth. Ao contrário das demais espécies do mesmo grupo, que são dotadas de capítulos globosos ou elípticos, as inflorescências de Mimosa barnebiana compõem nítidas espigas, com eixo floral de $3-5 \mathrm{~cm}$ (Barneby, 1991). No Brasil, a ocorrência natu- 
ral da espécie foi assinalada por Morales et al. (2015) em localidades esparsas dos estados do Rio Grande do Sul e Paraná, em solos úmidos à margem de estradas, capoeiras e áreas pantanosas ou esporadicamente inundadas.

Arbustos inermes de 1-4 m de altura, Mimosa bifurca Benth. distribui-se do leste do Paraguai, nordeste da Argentina e leste de Santa Catarina até o centro do Uruguai. Trata-se de espécie inconfundível pelos parafilídios orbicular-reniformes, bem como pelos folíolos sésseis e em disposição alterna nas pinas, com pontos glandulares (glutinosos) impressos, visíveis em ambas as faces (Barneby, 1991). Distintamente de Mimosa barnebiana, em Mimosa bifurca as flores encontram-se em capítulos, à semelhança das demais espécies da série Stipellares. Para o Rio Grande do Sul - e sob o nome de Mimosa hassleriana Chod., atualmente reduzido à sinonímia -, Rambo (1966) registrou coletas em terras altas do Nordeste do estado (Canela, Nova Petrópolis, Caxias do Sul, Farroupilha, Garibaldi), em Nonoai (curso superior do Rio Uruguai), na costa litorânea (Curralinhos, "perto de Torres"), bem como nos municípios de Jari, Santa Maria e Rosário do Sul.

Com relação à estrutura do lenho, Cozzo (1951) registrou uma ampla variação anatômica em Mimosa L., salientando a inexistência de uma característica peculiar, comum a todas as espécies do gênero. Apesar da reduzida literatura atualmente disponível, fato que se explica pelo pequeno porte de grande parte de suas espécies lenhosas e o escasso valor econômico da maioria das mesmas, a diversidade estrutural referida na literatura equivale ao descrito para toda a subfamília Mimosoideae (Marchiori, 1980).

No tocante à série Stipellares, destacam-se os estudos sobre Mimosa cruenta (Marchiori, 1985), Mimosa uraguensis (Marchiori 1996b) e Mimosa trachycarpa (Marchiori, 1997), que registraram, no lenho das três espécies, a predominância de poros em múltiplos, com tendência a arranjo diagonal (dendrítico). O mesmo traço anatômico se pode observar na "clave para el reconocimiento anatómico de los géneros y espécies de Mimosoideas y Caesalpinioideas argentinas", em que Cozzo (1951) assinalou porosidade dendrítica para os lenhos de Mimosa cruenta, Mimosa hassleriana (atual M. bifurca) e Mimosa uraguensis; e poros "em sua maioria" agrupados para Mimosa uliginosa. Apesar da não citação do caráter em espécies de outras séries botânicas, o autor não tece qualquer comentário sobre o valor taxonômico do mesmo.

\section{MATERIAIS E MÉTODOS}

O material estudado consiste de amostras de madeira e exsicatas botânicas conservadas na Xiloteca e Herbário do Departamento de Ciências Florestais da Universidade Federal de Santa Maria com os seguintes registros:

- HDCF 7373. Mimosa barnebiana Fortunato \& Tressens. Leg.: Kettenhuber, P.L.W., 2703-2016, Aratiba, RS; com flores e frutos; det.: Sobral, M.

- HDCF 2949. Mimosa bifurca Benth. (sob o nome de Mimosa hassleriana Chod., reduzido, atualmente, à sinonímia). Leg.: Marchiori, J.N.C. n. 569, 04-10-1986, Cerro do Loreto, São Vicente do sul, RS. Flores rosadas. Madeira coletada.

Do material lenhoso foram preparados três corpos-de-prova $(1 \times 2 \times 3 \mathrm{~cm})$ de cada uma das amostras de madeira, orientados para a obtenção de cortes anatômicos nos planos transversal, longitudinal radial e longitudinal tangencial; um quarto bloquinho foi também preparado, com vistas à maceração.

A confecção de lâminas de cortes anatômicos seguiu a metodologia descrita em Burger \& Richter (1991), usando-se, como corantes, uma mistura de Acridina-Vermelha e Crisoidina num primeiro banho, e Azul-de-Astra no segundo (Dujardin, 1964). Para as lâminas de macerado adotou-se o método de Jeffrey (Freund, 1970), colorindo-se a pasta de fibras apenas com Safranina. Com vistas ao preparo de lâminas permanentes, usou-se "Entellan", nos dois tipos de lâminas. 
As descrições basearam-se nas recomendações da IAWA (Wheeler et al., 1989). No tocante à percentagem dos tecidos e largura de raios em número de células foram realizadas 600 determinações ao acaso, com auxílio de contador de laboratório, conforme proposto por Marchiori (1980). A frequência de poros foi obtida a partir de um quadrado de área conhecida, superposto a fotomicrografias em diferentes pontos da seção transversal.

As medições da estrutura anatômica foram realizadas em microscópio fotônico Carl Zeiss, no Laboratório de Anatomia da Madeira da Universidade Federal de Santa Maria. As imagens que ilustram o texto foram tomadas em fotomicroscópio Leica DM 1000, equipado com câmera digital Olympus Camedia CX 40, no Laboratório de Anatomia da Madeira do Centro de Educação Superior Norte do Rio Grande do Sul (CESNORS - UFSM), em Frederico Westphalen. Na citação de características quantitativas, os números entre parênteses correspondem aos valores mínimos e máximos observados; o valor que acompanha a média é o desvio padrão.

\section{DESCRIÇÃO DAS MADEIRAS}

A estrutura anatômico-microscópica do lenho das duas espécies em estudo é a seguir apresentada, por ordem alfabética de nomes científicos.

\section{Mimosa barnebiana Fortunato \& Tressens}

Anéis de crescimento: distintos.

Vasos: numerosos (131 \pm 37 (84-220) poros $/ \mathrm{mm}^{2}$ ), ocupando $17 \pm 2,4 \%$ do volume da madeira. Porosidade difusa. Poros em arranjo tendente a dendrítico, compondo múltiplos racemiformes, menos comumente radiais e tangenciais ( $84 \%$ do total), com poucos solitários (16\%); circulares ou ovais (47 \pm 19 (18$85) \mu \mathrm{m}$ e de paredes finas a espessas $(3,5 \pm 1,2$ $(1,2-6,2) \mu \mathrm{m})$ (Figura 1A,B). Elementos vasculares curtos $(201 \pm 48(70-300) \mu \mathrm{m})$, com placas de perfuração simples, oblíquas ou transversais ao vaso, e apêndices ausentes ou, então, curtos $(19 \pm 18(10-70) \mu \mathrm{m})$. Pontoações intervasculares pequenas e arredondadas $(6,1 \pm$ $0,7(5,1-7,2) \mu \mathrm{m})$, alternas, ornamentadas, com aberturas em fenda inclusa, cruzadas em " $X$ " no par. Pontoações raio-vasculares, semelhantes às intervasculares, embora menores $(3,9 \pm$ $0,7(3,1-5,1) \mu \mathrm{m})$. Espessamentos espiralados, ausentes. Conteúdos, presentes.

Parênquima axial: paratraqueal escasso, representando $5 \pm 2,2 \%$ do volume da madeira. Conteúdos, não observados. Células fusiformes de $222 \pm 34$ (175-300) $\mu \mathrm{m}$ de altura. Séries parenquimáticas de $235 \pm 37$ (188-375) $\mu \mathrm{m}$ de altura, com 2-4 células (Figura 1F). Cristais, ausentes.

Raios: numerosos (10 \pm 2 (8-14) raios $/ \mathrm{mm})$, ocupando $21 \pm 4 \%$ do volume da madeira; estreitos $(21 \pm 5(15-38) \mu \mathrm{m})$ e homogêneos, compostos inteiramente de células procumbentes (Figura 1C,D). Os unisseriados, predominantes (54\%), de $128 \pm 62$ (38-288) um e 3-21 células de altura. Os multisseriados, bisseriados (44\%), menos comumente trisseriados (2\%); de $355 \pm$ 139 (187-675) $\mu \mathrm{m}$ e 15-47 células de altura. Células radiais de contorno arredondado, em plano tangencial; células radiais de paredes disjuntas e células perfuradas, ausentes. Raios fusionados e conteúdos, presentes.

Fibras: libriformes, de $574 \pm 74$ (450-800) $\mu \mathrm{m}$ de comprimento, com $13 \pm 2,6(7,5-16) \mu \mathrm{m}$ de largura, e paredes finas $(2,4 \pm 0,69(1,3-3,8)$ $\mu \mathrm{m})$, ocupando $57 \pm 6 \%$ do volume da madeira (Figura 1B). Fibras gelatinosas, presentes; espessamentos espiralados, fibras septadas e traqueídeos, ausentes.

Outros caracteres: variantes cambiais, tubos laticíferos e taniníferos, canais intercelulares, células oleíferas, células mucilaginosas, estratificação e máculas medulares, ausentes.

\section{Mimosa bifurca Benth.}

Anéis de crescimento: distintos.

Vasos: extremamente numerosos $(208 \pm 36$ (150-270) poros $/ \mathrm{mm}^{2}$ ), ocupando $14 \pm 2,4 \%$ do volume da madeira. Porosidade, difusa. Poros em arranjo tendente a dendrítico, em múltiplos 

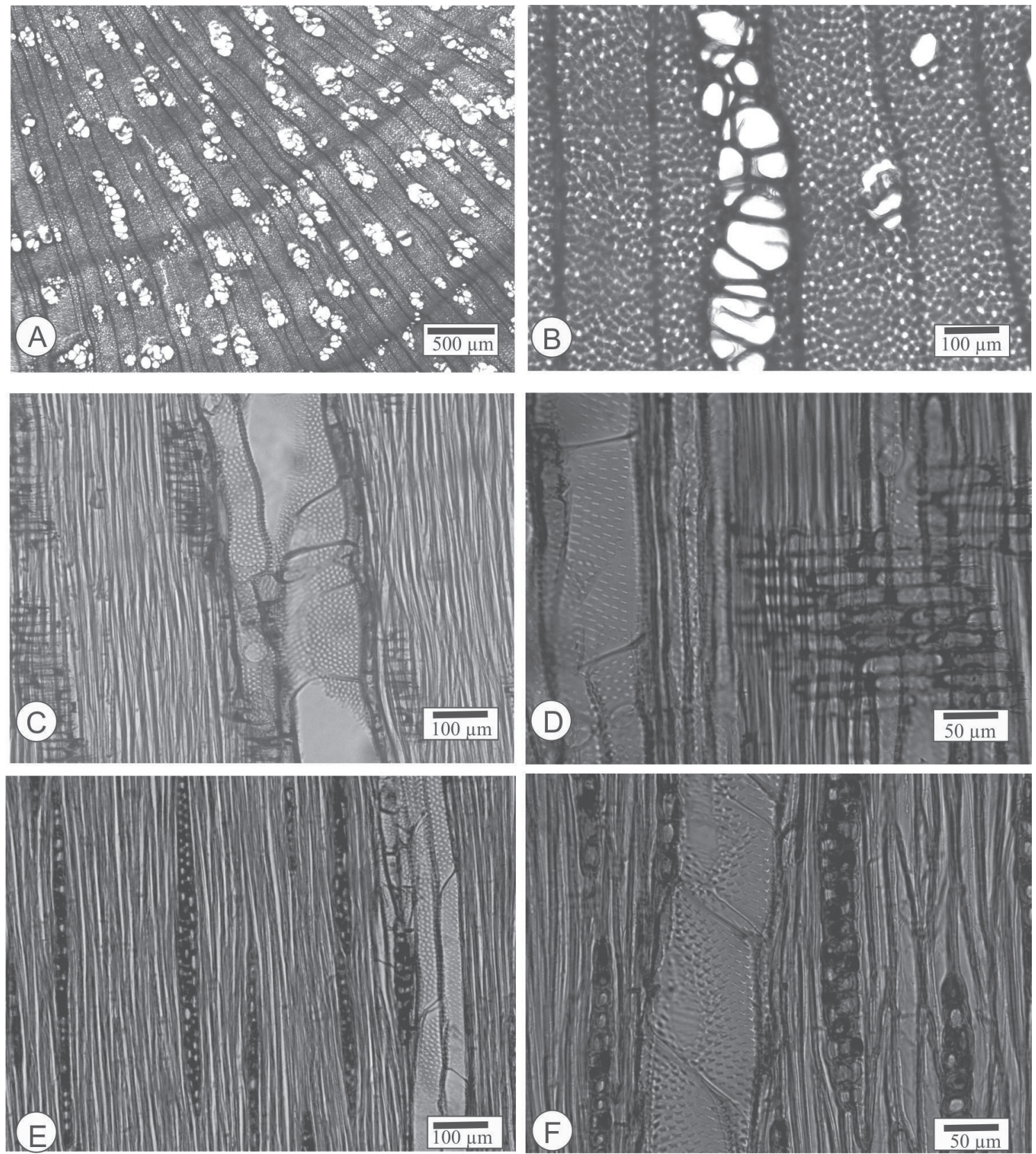

Figura 1 - Fotomicrografias do lenho de Mimosa barnebiana. A - Porosidade difusa, poros em múltiplos racemiformes, poucos solitários; anel de crescimento distinto (seção transversal). B - Detalhe de poros e parênquima paratraqueal escasso (seção transversal). C - Raios homogêneos, compostos de células procumbentes, e elementos vasculares (seção radial). D - Mesmo plano, em maior aumento, exibindo vaso e parênquima axial seriado. E - Raios uni e bisseriados, e parênquima axial (seção tangencial). F - Elemento vascular com placas de perfuração simples, pontoações alternas ornamentadas e raios estreitos (seção tangencial) 
racemiformes, menos comumente radiais e tangenciais ( $80 \%$ do total), com poucos solitários (20\%); circulares ou ovais (47 \pm 11 (25-65) $\mu \mathrm{m}$ e de paredes finas a espessas $(3,2 \pm 0,8(2,5$ $5,0) \mu \mathrm{m})$ (Figura 2A,B). Elementos vasculares curtos $(173 \pm 36(130-260) \mu \mathrm{m})$, com placas de perfuração simples, oblíquas ou transversais ao vaso; apêndices curtos $(14 \pm 5(10-20) \mu \mathrm{m})$. Pontoações intervasculares pequenas e arredondadas $(5,5 \pm 0,5(4,6-6,2) \mu \mathrm{m})$, alternas, com abertura em fenda inclusa, cruzadas em " $\mathrm{X}$ " no par (Figura 2F). Pontoações raio-vasculares, semelhantes às intervasculares, embora menores $(4,5 \pm 0,3(4,1-5,2) \mu \mathrm{m})$. Espessamentos espiralados, ausentes. Conteúdos, presentes.

Parênquima axial: representando $20 \pm 4,4 \%$ do volume da madeira; paratraqueal, concentrado no lado dos agrupamentos de vaso voltado para o término dos anéis, por vezes compondo segmentos que se estendem por vários raios; no lado oposto dos agrupamentos de vaso, predomina o contato vaso/fibras (Figura 2A, B). Conteúdos, escassos. Células fusiformes de 198 \pm 32 (150-250) $\mu \mathrm{m}$ de altura. Séries parenquimáticas de $174 \pm 22(125-213) \mu \mathrm{m}$ de altura, composto de 2 células (Figura 2F). Cristais, ausentes.

Raios, numerosos $(12 \pm 1,9(8-16)$ raios/ $\mathrm{mm}$, ocupando $14 \pm 2,4 \%$ do volume da madeira; estreitos (21 \pm 3 (18-28) $\mu \mathrm{m})$ e homogêneos, compostos inteiramente de células procumbentes (Figura 2C, D). Os unisseriados, predominantes (77\%), de $135 \pm 64(43-275) \mu \mathrm{m}$ e 2-18 células de altura. Os bisseriados (23\%), de $175 \pm 41$ (113-263) um e 6-18 células de altura. Células radiais de contorno arredondado, em plano tangencial; células envolventes, células radiais de paredes disjuntas e células perfuradas de raio, ausentes. Raios fusionados e conteúdos, presentes.

Fibras: libriformes, de $515 \pm 101$ (270-750) $\mu \mathrm{m}$ de comprimento, com $10 \pm 1,7(7,5-12,5)$ $\mu \mathrm{m}$ de largura, e paredes finas $(2,6 \pm 0,6(1,2-$ $3,1) \mu \mathrm{m})$, ocupando $52 \pm 7 \%$ do volume da madeira (Figura 2B). Fibras gelatinosas, presen- tes; espessamentos espiralados, fibras septadas e traqueídeos, ausentes.

Outros caracteres: variantes cambiais, tubos laticíferos e taniníferos, canais intercelulares, células oleíferas, células mucilaginosas, estratificação e máculas medulares, ausentes.

\section{DISCUSSÃO}

Os lenhos de Mimosa barnebiana e Mimosa bifurca reúnem caracteres anatômicos de ampla ocorrência em Leguminosas Mimosóideas (Fabaceae), salientando-se: porosidade difusa; placas de perfuração simples; pontoações arredondadas, ornamentadas e em arranjo alterno; parênquima paratraqueal; fibras libriformes; e raios homogêneos, compostos inteiramente de células procumbentes. A respeito da anatomia do lenho em Mimosa L., Cozzo (1951) resumiu que a diversidade observada em estudo de 13 espécies da Argentina corresponde ao descrito para toda a subfamília Mimosoideae.

Nas duas espécies presentemente descritas salienta-se a predominância de vasos em múltiplos, com tendência ou em nítido arranjo diagonal, aspecto que, embora pouco freqüente no gênero em estudo, foi anteriormente registrado nos lenhos de Mimosa cruenta (Marchiori, 1985), M. uraguensis (Marchiori, 1996b) e Mimosa trachycarpa (Marchiori, 1997). Também Cozzo (1951), em sua "clave para el reconocimiento anatómico de los géneros y espécies de Mimosoideas y Caesalpinioideas argentinas", assinalou a ocorrência de porosidade dendrítica em Mimosa cruenta, M. hassleriana (atual M. bifurca) e M. uraguensis, e poros "em sua maioria" agrupados em M. uliginosa. Cabe salientar que todas essas espécies incluem-se na série Stipellares Benth. e que o caráter não consta na literatura para espécies de outros táxons infragenéricos de Mimosa L.

Poros em múltiplos racemiformes é caráter aparentemente ausente na série Calothamnos Barneby, uma vez que o mesmo não foi registrado em Mimosa berroi Burkart (Marchiori, 1996a), M. eriocarpa Benth. (Carnieletto \& 

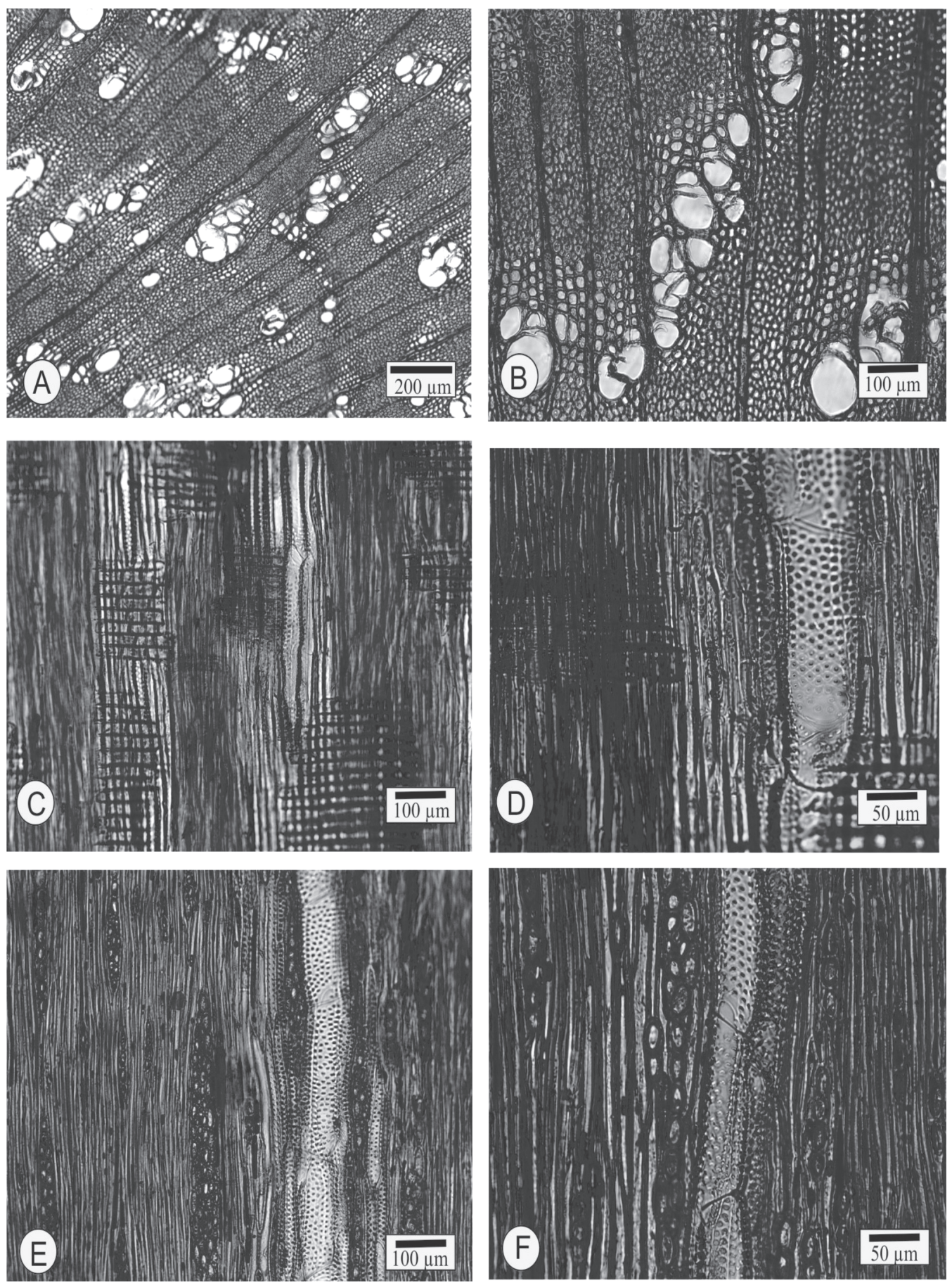

Figura 2 - Fotomicrografias do lenho de Mimosa bifurca. A - Porosidade difusa, poros em arranjo tendente a dendrítico, com poucos solitários; anel de crescimento distinto (seção transversal). B - Detalhe de poros em múltiplos racemiformes e parênquima paratraqueal (seção transversal). C - Raios homogêneos compostos de células procumbentes, e elementos vasculares (seção radial). D - Mesmo plano, em maior aumento, salientando vaso e parênquima axial seriado. E - Raios unisseriados e bisseriados, parênquima axial (seção tangencial). F - Elemento vascular com placas de perfuração simples, pontoações alternas ornamentadas e raios estreitos (seção tangencial) 
Marchiori, 1993), M. flocculosa Burkart (Pereira et al., 2013), M. incana Benth. (Marchiori, 1996), M. pilulifera Benth.(Marchiori, 1997) e M. scabrella Benth. (Mainieri \& Chimello, 1989; Marchiori, 1995; Paraná, 1979; Richter \& Charvet, 1973). Em espécies da série Mimo$s a$ L. e subsérie Obstrigosae (Benth.) Barneby, o referido caráter anatômico também não foi assinalado para Mimosa adpressa (Cozzo, 1951), M. parvipinna Benth. (Machado \& Marchiori, 2016) e M. ramulosa Benth. (Machado \& Marchiori, 2016). Ressalta-se, igualmente, que o caráter também não ocorre em Mimosa sparsa Benth. (Maccari \& Marchiori, 1994), da série Mimosa L. e subsérie Sparsae, nem em Mimosa micropteris Benth. (Siegloch et al., 2013), da série Myriophyllae Benth., e M. bimucronata (DC.) Kuntze (Marchiori, 1993), da série Bimucronatae Barneby.

A confirmação de poros em múltiplos racemiformes nas duas espécies presentemente descritas - e com tendência, ou nítido arranjo diagonal -, assume, por conseguinte, grande valor diagnóstico para a série Stipellares Benth., sobretudo pela não ocorrência do caráter em espécies de outros grupos infragenéricos de Mimosa L., até o momento conhecidas. Pelo número de espécies já descritas, pode-se afirmar, inclusive, que a série Stipellares Benth., sob o ponto de vista da anatomia da madeira, constitui um grupo homogêneo e distinto dos demais táxons infragenéricos de Mimosa L., sejam eles os constantes no esquema de George Bentham, ou de Rupert C. Barneby.

Apesar do conhecido valor adaptativo do agrupamento de vasos a condições áridas, por favorecer a segurança condutiva e prevenir cavitações (Lindorf, 1994; Santos, 2008), o referido caráter dificilmente seria justificado no caso de Mimosa barnebiana, espécie típica de campos inundados e áreas alagadiças. O ponto cresce em importância quando se verifica a ausência do caráter nas espécies anteriormente citadas da subsérie Obstrigosae, que em sua maioria habitam sítios pedregosos e exibem um conjunto maior de caracteres externos vinculados à xeromorfia. A presença do mesmo em todas as espécies descritas da série Stipellares Benth. - e tão somente em espécies deste grupo, dentro do gênero Mimosa -, permite concluir que o caráter tem real valor taxonômico para esta série botânica, permitindo segregá-la dos demais táxons do gênero.

Com relação à estrutura radial, o lenho das duas espécies em estudo, à semelhança de outras da mesma série botânica, apresentam apenas células procumbentes, em contraste com o descrito para Mimosa parvipinna e M. ramulosa por Machado \& Marchiori (2016), entre outros autores. Se esse aspecto anatômico indica maior especialização dos raios na série Stipellares, tendência reconhecida por Baretta-Kuipers (1981) como distintiva da subfamília Mimosoideae no conjunto das Leguminosae (Fabaceae), a diversidade observada neste quesito, em espécies de outros grupos infragenéricos, comprova a diversidade estrutural atribuída por Cozzo (1951) ao gênero Mimosa.

Tanto em Mimosa barnebiana como em $M$. bifurca, por outro lado, não se verifica a ocorrência de estratificação, em contraste com referência de Cozzo (1948) para Mimosa adpressa (da seção Mimosa L., série Mimosa L. e subsérie Obstrigosae (Benth.) Barneby) e para Mimosa scabrella (seção Calothamnos Barneby). Segundo Carlquist (1962), a estratificação completa ou de parte dos elementos anatômicos indica alta especialização do xilema e surgiu, independentemente, diversas vezes em Angiospermas Dicotiledôneas. Os fundamentos para a interpretação filogenética desse caráter foram estabelecidos por Bailey $(1920,1923)$ e derivam do plano de divisão das células iniciais do câmbio, posto que divisões raio-longitudinais não implicam alongamento apical durante a diferenciação celular, dando origem à estratificação e, inclusive, a elementos vasculares mais curtos, caráter indiscutivelmente especializado. 


\section{REFERÊNCIAS BIBLIOGRÁFICAS}

BAILEY, I.W. The cambium and its derivative tissues. III. A reconnaissance of cytological phenomena in the cambium. American Journal of Botany, St. Louis, n. 7, p. 417-434, 1920.

BAILEY, I.W. The cambium and its derivative tissues. IV. The increase in girth of the cambium. American Journal of Botany, St. Louis, n. 10, p. 499-509, 1923.

BARETTA-KUIPERS, T. Wood anatomy of Leguminosae: its releevance to Taxonomy. In: POLHILL, R.M., RAVEN, P.H. Advances in Legume Systematics. Kew: Royal Botanic Gardens, 1981. p. 677-715.

BARNEBY, R.C. Sensitivae censitae: a description of the Genus Mimosa Linnaeus (Mimosaceae) in the New World. Memoirs of the New York Botanical Garden, New York, v. 65, p. 1-835, 1991.

BENTHAM, G. Notes on Mimoseae, with a synopsis of species. Transactions of the Linnean Society of London, n. 1, p. 318-392, 494-518, 1842.

BENTHAM, G. Revision of the sub-order Mimoseae. Transactions of the Linnean Society of London, n. 30, p. 335-664, 1875.

BENTHAM, G. Leguminosae. III Mimoseae. In: MARTIUS, C.F.P. von. Flora Brasiliensis. 1876. v. 15 , fasc. 2 , p. 259-527.

BESSEGA, C; HOPP, H.E.; FORTUNATO, R.H. Toward a phylogeny of Mimosa (Leguminosae: Mimosoideae): a preliminary analysis of southern South American species based on chloroplast DNA sequence. Annals of the Missouri Botanical Garden, St. Louis, n. 95, p. 567-579, 2008.

BURGER , L.M.; RICHTER, H.G. Anatomia da Madeira. São Paulo: Ed. Nobel, 1991. 154 p.

BURKART, A. Las especies de Mimosa de la Flora Argentina. Darwiniana, San Isidro, v. 8, n. 1, p. 231, 1948.

CARNIELETTO, C.; MARCHIORI, J.N.C. Anatomia da madeira de Mimosa eriocarpa Benth. Ciência Florestal, Santa Maria, v. 3, n. 1, p. 107120, 1993.

CARLQUIST, S. Comparative Plant Anatomy: a guide to taxonomic and evolutionary application of anatomical data in Angiosperms. New York: Holt, Rinehart and Winston, 1962. 146 p.
COZZO, D. Anatomia del leño secundario de las Leguminosas Mimosoideas y Caesalpinioideas argentinas silvestres y cultivadas. Revista del Instituto Nacional de Investigación de las Ciencias Naturales (Ciencias Botánicas), Buenos Aires, v. 2, n. 2, p. 63-290, 1951.

COZZO, D. Estrutura leñosa estratificada no registrada en géneros de Leguminosas argentinas. Lilloa, Tucuman, v. 16, p. 63-95, 1948.

DE CANDOLlE, A.P. Prodromus Sistematis Naturalis Regni Vegetabilis. Paris: Sumptibus Sociorum Treuttel et Würtz, 1825. 644 p.

DUJARDIN, E.P. Eine neue Holz-Zellulosenfaerbung. Mikrokosmos, n. 53, p. 94, 1964.

FREUND, H. Handbuch der Mikroskopie in der Technik. Frankfurt: Umsham Verlag, 1970. 375 p.

LINDORF, H. Eco-anatomical wood features of species from a very dry tropical Forest. IAWA Bulletin, v. 15, p. 361-376, 1994.

LINNAEI, C. Genera Plantarum. Weinheim: H.R. Engelmann; Codicote: Weldon \& Wesley, 1960. 522p. (facsimile da $5^{\mathrm{a}}$ ed., 1754).

LUCKOW, M.; WHITE, P.J.; BRUNEAU, A. Relationships among the basal genera of Mimosoids legumes. In: HERENDEEN, P.S.; BRUNEAU, A. (eds.). Advances in Legume Systematics. Kew: Royal Botanic Gardens, 2000. 9: $15-180$.

MACCARI, A.; MARCHIORI, J.N.C. Estudo anatômico do xilema secundário de Mimosa sparsa Benth. Ciência Florestal, Santa Maria, v. 4, n. 1, p. 145-155, 1994.

MACHADO, P.F. dos S.; MARCHIORI, J.N.C. Anatomia do lenho de duas espécies sulbrasileiras do gênero Mimosa L. e subsérie Obstrigosae (Benth.) Burkart. Balduinia, Santa Maria, n. 52, p. 22-29, 2016.

MAINIERI, C. Madeiras do litoral sul: estados de São Paulo, Paraná e Santa Catarina Nomenclatura botânica e vulgar, características gerais e usos comuns. São Paulo: Secretaria da Agricultura, 1973.84 p.

MARCHIORI, J.N.C. Estudo anatômico do xilema secundário e da casca de algumas espécies dos gêneros Acacia e Mimosa, nativas no estado do Rio Grande do Sul. Dissertação (Mestrado em Engenharia Florestal). Curitiba: Universidade Federal do Paraná, 1980. 186 f. 
MARCHIORI, J.N.C. A estrutura do xilema secundário de Mimosa daleoides Benth. (Leguminosae Mimosoideae). Ciência e Natura, Santa Maria, n. 4, p. 107-113, 1982.

MARCHIORI, J.N.C. Anatomia da madeira de Mimosa cruenta Benth. (Leguminosae Mimosoideae). Ciência e Natura, Santa Maria, n. 7, p. 73-81, 1985.

MARCHIORI, J.N.C. Anatomia da madeira e casca do maricá, Mimosa bimucronata (DC.) O. Kuntze. Ciência Florestal, Santa Maria, v. 3, n. 1, p. 85-106. 1993.

MARCHIORI, J.N.C. Anatomia da madeira e casca da bracatinga, Mimosa scabrella Benth. Ciência e Natura, Santa Maria, n. 17, p. 115-132, 1995.

MARCHIORI, J.N.C. Anatomia do xilema secundário de Mimosa berroi Burkart. Ciência e Natura, Santa Maria, n. 18, p. 117-129, 1996a.

MARCHIORI, J.N.C. Anatomia do xilema secundário de Mimosa uruguensis Hook. \& Arn. Ciência e Natura, Santa Maria, n. 18, p. 103115, $1996 \mathrm{~b}$.

MARCHIORI, J.N.C.; MUÑIZ, G.I.B. de. Estudo anatômico do xilema secundário de Mimosa trachycarpa Benth. Ciência Rural, Santa Maria, v. 27, n. 2, p. 223-228, 1997a.

MARCHIORI, J.N.C.; MUÑIZ, G.I.B. de. Estudo anatômico do xilema secundário de Mimosa pilulifera Benth. Ciência Florestal, Santa Maria, v. 7, n. 1, p. 65-75, 1997b.

MORALES, M.; RIBAS, O.S.; FORTUNATO, R.H. Increasing reports in Mimosa (Mimosoideae, Leguminosae) for the Brazilian Flora. Boletín de la Sociedad Argentina de Botánica, Córdoba, v. 50, n. 2, p. 221-233, 2015.

PARANÁ. Universidade Federal do. Centro de Pesquisas Florestais. Estudo das alternativas técnicas, econômicas e sociais para o setor florestal do Paraná. Sub-programa Tecnologia. Curitiba, 1979. 335f.

PEREIRA, A.C. da S.; SIEGLOCH, A.M.; MARCHIORI, J.N.C. Anatomia do lenho de Mimosa flocculosa Burkart. Balduinia, Santa Maria, n. 43, p. 29-33, 2013.

PLUMIER, C. Nova Plantarum Americanarum Genera. Paris: Joannem Boudot, 1703. 21 p.

RAMBO, B. Leguminosae Riograndenses. Pesquisas
(Botânica), São Leopoldo, n. 23, p. 1-166, 1966.

RICHTER, H.G.; CHARVET, L.M. Estudo e pesquisa sobre Mimosa scabrella. Floresta, Curitiba, v. 4, n. 2, p. 68-69, 1973.

SANTOS, S.R. dos. Estudo anatômico do lenho e descrição morfológica de cinco espécies sul-riograndenses da família Rhamnaceae. Dissertação (Mestrado em Engenharia Florestal). Santa Maria: Universidade Federal de Santa Maria, 2008. $120 \mathrm{f}$.

SANTOS-SILVA, J.; FRAGOMENI, S.M.; TOZZI, A.M.G. de A. Revisão taxonômica das espécies de Mimosa ser. Leiocarpae sensu lato (Leguminosae - Mimosoideae). Rodriguésia, Rio de Janeiro, v. 66, n. 1, p. 95-154, 2015.

SIEGLOCH, A.M.; MARCHIORI, J.N.C.; SANTOS, S.R. Anatomia do lenho de Mimosa micropteris Benth. Balduinia, Santa Maria, n. 40, p. 18-22, 2013.

SIMON, M.F.; GRETHER, R.; QUEIROZ, L.P.; SÄRKINEN, T.E.; DUTRA, V.F.; HUGHES, C.E. The evolutionary history of Mimosa (Leguminosae): toward a phylogeny of the sensitive plants. American Journal of Botany, St. Louis, n. 98, p. 1201-1221, 2011.

SULAIMAN, S.F.; CULHAM, A.; HARBORNE, J.B. Molecular phylogeny of Fabaceae based on rbcL sequence data: with special emphasis on the tribe Mimoseae (Mimosoideae). Asia-Pacific Journal of Molecular Biology and Biotechnology, Kuala Lampur, n. 11, p. 9-35, 2003.

TORTORELLI, L.A. Maderas y bosques argentinos. Buenos Aires: ACME, 1956. 910 p.

TOURNEFORT, P. Elemens de Botanique ou methode pour connoître les plantes. Paris: L'Imprimerie Royale, 1694. 379 p.

WHEELER, E.A.; BAAS, P.; GASSON, P.E. IAWA list of microscopic features for hardwood identification. IAWA Bulletin, v. 10, n. 3, p. 218359, 1989.

WILLDENOW, C.L. Caroli a Linné Species Plantarum: exhibentes plantas rite cognitas ad genera relatas cum differentiis specificis, nominibus trivialibus, synomymis selectis, locis natalibus secundum systema saexuale digestas. Berolini (Berlim): Impensis G.C. Nauk, 1805. v. 4. p. 1049-1093. 